\title{
Use of Telehealth in Mental Health (MH) Services During and After COVID-19
}

\author{
Todd Molfenter $^{1} \mathbb{D} \cdot$ Thomasine Heitkamp $^{2}$. Ann A. Murphy ${ }^{3} \cdot$ Stephanie Tapscott $^{4}$ - Stephanie Behlman ${ }^{1}$. \\ Olivia J. Cody ${ }^{1}$
}

Received: 12 December 2020 / Accepted: 10 June 2021 / Published online: 24 June 2021

(c) The Author(s) 2021

\begin{abstract}
COVID-19 social distancing guidelines caused a rapid transition to telephone and video technologies for the delivery of mental health $(\mathrm{MH})$ services. The study examined: (a) adoption of these technologies across the MH service continuum; (b) acceptance of these technologies; and (c) intention of providers to use these technologies following the pandemic based on a sample of $327 \mathrm{MH}$ organizations from 22 states during May-August 2020. There was widespread use of technology, with greater than $69 \%$ of organizations reporting using telephone or video for most services. For all video services and just three telephone services, organizations reported significantly greater odds of intending to use technology to deliver services post-COVID-19. Use of video was seen as more desirable as compared to telephone. The overall perceived ease of use and usefulness for video-based services and certain telephone services provide a promising outlook for use of these services post the COVID-19 pandemic.
\end{abstract}

Keywords Telehealth $\cdot$ Mental health $\cdot$ Behavioral health $\cdot$ Technology adoption

\section{Introduction}

The World Health Organization's declaration of the Public Health Emergency of International Concern (PHEIC) (World Health Organization, 2020), due to the spread of COVID-19, created immediate opportunities and challenges for mental health providers. The concerns included increased physical, mental, and psychological harm among our citizenry (Wang et al., 2020) and a greater need for mental health services. Recent data underscore the importance of triaging mental health care to people at greatest risk, including young adults,

Todd Molfenter

todd.molfenter@chess.wisc.edu

1 University of Wisconsin - Madison, 1513 University Ave., Madison, WI, USA

2 College of Nursing and Professional Disciplines, 400 Oxford Street, Grand Forks, ND 58202, USA

3 Department of Psychiatric Rehabilitation and Counseling Professions, Rutgers, School of Health Professions, 675 Hoes Lane West, Piscataway, NJ 08854, USA

4 Department of Health Policy and Management, Rollins School of Public Health, Emory University, 1518 Clifton Rd, Atlanta, GA 30322, USA racial/ethnic minorities, essential workers, and unpaid caregivers (Czeisler et al., 2020). In conjunction with the need for increased services, physical distancing was needed to lessen the spread of the COVID-19 virus.

The PHEIC was an opportunity for mental health providers to revisit their models of emergency and disaster response. It included an immediate call to action among administrators to support clinicians' professional development as they continued to provide individual, family, and group assessments/diagnosis and therapy to socially isolated clients. The challenge for administrators was to determine organizational and individual readiness to change and assess capacity to diversify their structures for delivering care at a distance while significant uncertainty existed (Waldeck et al., 2020). Social distancing mandates demanded expanded use of telehealth to deliver services safely while maintaining access, efficacy, and engagement.

Telehealth includes both video and telephone connections between the provider and client/patient. Mental health services providers may refer to this type of delivery as telemental health, telepsychiatry, teletherapy, or telepsychology. Of note, use of this technology to deliver services is not new. However, implementing telehealth has been gradual, with efforts beginning in the 1960s and 1970s. Early adopters 
were required to pay for expensive equipment. Additionally, some government-funded programs encouraged expanding access to telehealth, but that model of care delivery dissipated when funding was no longer available (Shore et al., 2020). Barnett and Huskamp (2020) found that early telehealth services were provided primarily in rural states, underserved counties, and among clinicians employed in publicly owned facilities. Nevertheless, telehealth has increased over time, albeit somewhat limited. This includes use of telehealth among substance use disorder treatment providers, especially in rural areas (Uscher-Pines et al., 2020).

Since the beginning of the pandemic, however, the use of telehealth has increased substantially (American Psychiatric Association, 2020). Clinicians responded to the PHEIC by moving their practice online. For example, a June 2020 study published by the American Psychological Association (2020) found that $75 \%$ of the respondents to a survey were solely providing remote services, including therapy by telephone, telehealth platforms, or videoconferencing. That same percentage felt confident in their use of telehealth. Professional associations have supported this shift by updating their web pages with a host of content about telehealth guidelines that existed in the public domain and began to expand access to information, including frequent updates on changing federal guidelines (American Psychiatric Association, 2020).

The advantages of telehealth are included extensively in commentaries and trainings on this topic (Edirippulige \& Armfield, 2017; Moore \& Munroe, 2020). They include increased access and availability to care, convenience for both consumers and providers, a decrease in no shows, an increase in consumer demand, an increase in affordable and useable technology platforms, reduction in the risk of coronavirus transmission, and the ability to view the person in their environment (Benavides-Vaello et al., 2013; Pruitt et al., 2014). Additionally, existing literature underscored the proven efficacy of telehealth delivery with outcomes similar to in-person therapy delivered in an office setting (Bashshur et al., 2016; Hilty et al., 2013; Langarizadeh et al., 2017).

The disadvantages of telehealth relate to concerns about billing practices, state licensing requirements that prevent work across state borders, and confidentiality and privacy concerns. Additional disadvantages include lack of bandwidth for access to technology in some homes and areas, negative impact on the therapeutic relationship, and problems treating certain populations using telehealth (American Telemedicine Association, 2020; Ramirez et al., 2020). Petersen et al. (2020) describe the limitation of the research on client and clinician satisfaction, noting clinicians have greater concern about use of telehealth than clients do, with both expressing concerns about efficacy, confidentiality, the impact on the therapeutic relationship, and technology concerns.

The PHEIC has provided an unprecedented need to apply telehealth services. Against the background of mixed preferences toward telehealth utilization, a deeper understanding is needed regarding how telehealth was applied during COVID-19 and treatment providers' reactions towards telehealth use. The manuscript focuses on mental health providers' comfort level in using telephone and video-based modalities, their readiness to use technology tools to deliver telehealth, and the projected use of telehealth beyond the COVID-19 PHEIC.

\section{Methods}

\section{Data Collection}

The survey link was distributed by email, and data collected May 15-August 31, 2020. The sample arose from individuals representing organizations in the Mental Health Technology Transfer Center's (MHTTC's) databases. The MHTTCs are Substance Abuse and Mental Health Services Administration (SAMHSA)-funded technical assistance centers whose purpose is to provide training and technical assistance to the mental health prevention, treatment, and recovery workforce in the United States. Four regional MHTTCs and four regions representing 22 states distributed this survey. Survey links were sent to respondents using an email script approved by the University of Wisconsin's Institutional Review Board (IRB). Individuals sent the survey link were either administrators of mental health programs or mental health clinicians (e.g., counselors, social workers, psychologists, case managers, and psychiatrists).

\section{Survey Instruments}

The survey included the following components and scales:

\section{Organizational Location and Type}

Locations included rural, small city, suburban, and urban. Organizational types included specialty behavior health and health systems.

\section{Organizational Role}

There were two categories of survey respondents: administrators and individuals who provide clinical services. These groupings were included because of their role in the adoption continuum. Administrators are often the decision-makers on whether telehealth will be offered as a service delivery 
option, and those who provide clinical services influence the ongoing daily use of telehealth for mental health services.

\section{Use of Telehealth}

(a) The use of telephone and video-based services was assessed for the following services: screening and assessment, case management, multi-disciplinary team-based services (e.g., Assertive Community Treatment), peer supports, group therapy, individual therapy, medication management, psycho-education, therapy services during partial hospitalization, and therapy sessions during residential treatment with a binary Yes/No response option; and b) The projected use of telephone and video services for each these services following COVID-19 was assessed asking respondents to what extent they plan to use telephone or video services beyond use to maintain COVID-19 safety measures, with response options of less than before, about the same, little more than before, or much more than before.

\section{Organizational Readiness for Technology Use}

The Organizational Readiness for Technology Use predictive tool developed by Gustafson et al. (2007) was applied to assess dimensions of organizational readiness for telephone and video technologies. The tool used a 5-point Likert scale with endpoints of Strongly Disagree and Strongly Agree. The inventory assessed reimbursement for the technology during and after COVID-19; billing expertise for the technology; information technology experts to support use of the technology; the ease of integrating the technology into workflow; having a clinical champion for the technology; having staff, facilities, and equipment in place to support the technology; leadership support; patient support; patient accessibility; technology affordability for patients; staff support; and staff training. These variables were assessed for telephone and video in general and not by each type of mental health service modality.

\section{Technology Acceptance}

The survey included scales from the Technology Acceptance Model (TAM) (Daniel et al., 2004; Venkatesh et al., 2003). This model measures Ease of Use and Perceived Usefulness. The Ease-of-Use scale assesses (a) if it is easy to get it to do what I want, (b) offering technology does not require a lot of effort, (c) easy to learn, and (d) easy to use. Perceived Usefulness assesses (a) enhances our effectiveness, (b) improves our performance, (c) increases our productivity, and (d) is useful. The scale's questions for the Perceived Usefulness and Ease of Use Variables had a 5-point Likert scale with endpoints of Strongly Disagree and Strongly Agree. The Intent to Use was a different 4-category ordinal scale with the selections: Following COVID-19, do you anticipate use of telephone/video for the following services will be: (a) less than before COVID-19 (1), (b) About the same (2), (c) a little more than before (3), (d) much more than before (4) or (e) N/A do not provide service.

\section{Data Analysis}

Frequency distribution statistics were used to describe survey response rate, organizational characteristics (setting and type), participant job roles, use of telephone and video technologies for different SUD services, and intent to use telephone and video technologies to deliver the different services post-COVID-19. Linear mixed-effects models (LMM) were conducted to determine if there were differences in intent to use telephonic and video technologies based on organizational location or setting and the survey respondent's role. For this analysis, a composite measure of the intent to use telephone and video technologies was created by averaging the intent to use scores across the different mental health services for each technology. The Intent to Use Telephone and Video technologies for the different services was analyzed using generalized linear mixed-effects models (GLMM) comparing "More Use" and "Little More Use" of the technology post-COVID-19 to "About the Same" and "Little Less" post-COVID-19. The Organizational Readiness for Technology Adoption variables were analyzed by comparing the Organizational Readiness for Technology Use factor scores between Telephone and Video using generalized linear mixed-effects models (GLMM) to determine factor differences between the technologies. Lastly, the TAM data was analyzed by conducting a mediational analysis of the Perceived Ease of Use and Perceived Usefulness variables compared to the composite Intent of Use variables for telephone and video services using linear regression. The analyses were conducted using the lme 4 package in $\mathrm{R}$ Studio.

\section{Results}

Three hundred and twenty-seven organizations were represented in the survey. Surveys were distributed to 1790 organizations that provide mental health services for a return rate of $18 \%$. The respondents' job categories were $50.8 \%$ administrators and $49.2 \%$ clinical services providers (Table 1). No significant difference appeared in the Intent to Use telephone or video services post-COVID-19 between the administrators and individuals who provide treatment and recovery services $(p=0.16)$. There were also no significant differences based on setting or organizational type. All reference variables, including the Administrator's category, 
Table 1 Organizational characteristics

\begin{tabular}{|c|c|c|c|c|c|c|c|c|c|}
\hline \multirow[t]{2}{*}{ Variable } & \multirow[t]{2}{*}{ Predictor } & \multirow[t]{2}{*}{$\mathrm{n}$} & \multirow[t]{2}{*}{$\%$} & \multicolumn{3}{|c|}{ Future intent phone } & \multicolumn{3}{|c|}{ Future intent video } \\
\hline & & & & Estimate & $95 \% \mathrm{Cl}$ & p-value & Estimate & $95 \% \mathrm{Cl}$ & p-value \\
\hline \multirow[t]{4}{*}{ Organizational setting } & Reference category: Rural & 101 & 30.9 & 2.78 & $2.58-2.97$ & $\mathrm{a}$ & 3.10 & $2.91-3.28$ & a \\
\hline & Small City & 70 & 21.4 & -0.23 & $-0.54-0.08$ & 0.14 & -0.05 & $-0.33-0.24$ & 0.74 \\
\hline & Suburban & 64 & 19.6 & 0.06 & $-0.25-0.37$ & 0.72 & -0.11 & $-0.40-0.18$ & 0.47 \\
\hline & Urban & 92 & 28.1 & 0.05 & $-0.24-0.33$ & 0.76 & 0.02 & $-0.25-0.29$ & 0.88 \\
\hline \multirow[t]{2}{*}{ Organizational type } & $\begin{array}{l}\text { Reference category: Specialty } \\
\text { Behavioral health }\end{array}$ & 254 & 77.7 & 2.76 & $2.64-2.89$ & a & 3.10 & $2.98-3.22$ & A \\
\hline & Health Systems & 73 & 22.3 & -0.06 & $-0.33-0.22$ & 0.68 & -0.12 & $-0.37-0.14$ & 0.37 \\
\hline \multirow[t]{2}{*}{ Job role } & Reference category: Administrator & 166 & 50.8 & 2.77 & $2.61-2.93$ & $\mathrm{a}$ & 3.14 & $3.00-3.29$ & a \\
\hline & Clinician & 161 & 49.2 & -0.06 & $-0.29-0.18$ & 0.64 & -0.15 & $-0.36-0.06$ & 0.16 \\
\hline
\end{tabular}

${ }^{a}$ All intercepts were significant (i.e., for each reference category the future intent to use phone/video was significantly different from 0 )

had future intent to use, or support use of phone and video that was significantly different from 0 .

The MH service that had the greatest percentage of telephone and video use was Individual Therapy at $89.8 \%$ for phone and $88.1 \%$ for video (Fig. 1). For the Intent to Use the technology, all the MH services had a positive odds ratio for wanting to use telephone or video technology "Much More" or a "Little More" following COVID-19 safety measures compared to using the technology the "About the Same" or a "Little Less" than before COVID-19 (Table 2). The odds ratios were not significant for using telephone for Group Therapy $(p=0.78)$, Medication Management $(p=0.18)$, or Multi-Disciplinary Team-Based $(\mathrm{p}=0.20)$. All odds ratios were significant for video services, and video services were seen as more favorable than telephone for all services.

Among the Organizational Readiness for Technology Use measures for telephone services, the factors that had the two highest ratings on the 5-point Likert scale were: (a)
Telephonic/video counseling is affordable to patients (4.02, 95\% Cl 3.89-4.14), and (b) Most of our patients can access telephonic/video technology $(3.97,95 \% \mathrm{Cl} 3.84-4.10)$ (Table 3). For video services, the top two were: (a) our leadership supports the implementation of video counseling (4.10, 95\% Cl 3.98-4.22), and (b) staff want video counseling to be sustained $(4.03,95 \% \mathrm{Cl} 3.71-3.97)$. The significant differences between these technologies were telephone was seen as more advantageous for: (a) most of our patients can access telephonic technology $(-0.87$, $95 \% \mathrm{Cl}-1.02-0.73, \mathrm{p}<0.001$ ), (b) patients find telephonic counseling is easy to use (OR $-0.46,95 \% \mathrm{Cl}-0.59-0.33$, $\mathrm{p}<0.001$ ), and (c) telephonic counseling is affordable to patients $(-0.23,95 \% \mathrm{Cl}-0.36-0.11, \mathrm{p}<0.001)$. Video was seen as more advantageous for (a) there is a clinical champion for the promotion of telephonic/video counseling $(0.31,95 \% \mathrm{Cl} 0.18-0.44, \mathrm{p}<0.001)$ and $(\mathrm{b})$ we anticipate being adequately reimbursed for the services we provide

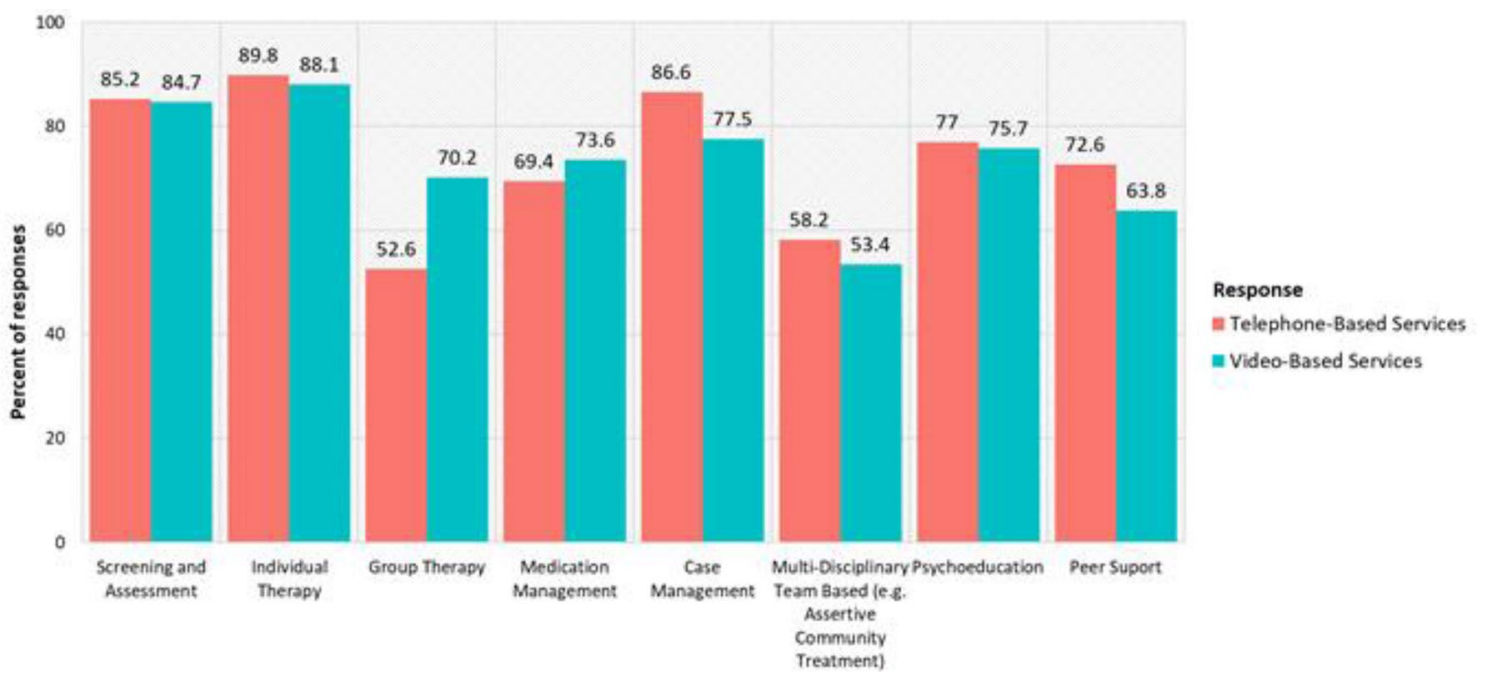

Fig. 1 Current use of telehealth by service 
Table 2 Odds of using telehealth post-COVID-19 safety measures

\begin{tabular}{|c|c|c|c|c|c|c|c|c|c|}
\hline & \multicolumn{3}{|c|}{ Telephone } & \multicolumn{3}{|l|}{ Video } & \multicolumn{3}{|c|}{ Video compared to telephone } \\
\hline & Estimate & $95 \% \mathrm{Cl}$ & p-value & Estimate & $95 \% \mathrm{Cl}$ & p-value & Estimate & $95 \% \mathrm{Cl}$ & p-value \\
\hline Screening and Assessment/Intake & 2.10 & $1.32-3.34$ & 0.002 & 7.10 & $3.93-12.82$ & $<0.001$ & 3.39 & $2.11-5.44$ & $<0.001$ \\
\hline Individual Therapy & 2.97 & $1.63-5.42$ & $<0.001$ & 14.26 & $6.37-31.94$ & $<0.001$ & 4.79 & $2.81-8.18$ & $<0.001$ \\
\hline Group Therapy & 0.94 & $0.62-1.42$ & 0.78 & 3.74 & $2.32-6.02$ & $<0.001$ & 3.96 & $2.39-6.58$ & $<0.001$ \\
\hline Medication Management & 1.37 & $0.87-2.15$ & 0.18 & 7.53 & $3.95-14.35$ & $<0.001$ & 5.51 & $3.01-10.08$ & $<0.001$ \\
\hline Case Management & 2.34 & $1.36-4.02$ & 0.002 & 5.23 & $2.79-9.78$ & $<0.001$ & 2.24 & $1.35-3.72$ & 0.002 \\
\hline $\begin{array}{l}\text { Multi-disciplinary Team Based (e.g. } \\
\text { Assertive Community Treatment) }\end{array}$ & 1.54 & $0.80-2.97$ & 0.20 & 4.31 & $2.04-9.10$ & $<0.001$ & 2.80 & $1.50-5.23$ & 0.001 \\
\hline Psychoeducation & 1.98 & $1.03-3.83$ & 0.041 & 8.37 & $3.68-19.00$ & $<0.001$ & 4.22 & $2.35-7.55$ & $<0.001$ \\
\hline Peer Support & 2.43 & $1.35-4.36$ & 0.003 & 5.42 & $2.76-10.66$ & $<0.001$ & 2.23 & $1.31-3.81$ & 0.003 \\
\hline
\end{tabular}

Table 3 Organizational readiness for telephone and video use

\begin{tabular}{|c|c|c|c|c|c|c|c|}
\hline \multirow[b]{2}{*}{ Question } & \multicolumn{2}{|c|}{ Telephone } & \multicolumn{2}{|l|}{ Video } & \multicolumn{3}{|c|}{ Video compared to telephone } \\
\hline & Estimate & $95 \% \mathrm{Cl}$ & Estimate & $95 \% \mathrm{Cl}$ & Estimate & $95 \% \mathrm{Cl}$ & p-value \\
\hline $\begin{array}{l}\text { Our leadership supports the implementation of telephonic/ } \\
\text { video counseling }\end{array}$ & 3.96 & $3.84-4.08$ & 4.10 & $3.98-4.22$ & 0.14 & 0.03 to 0.25 & 0.011 \\
\hline $\begin{array}{l}\text { There is a clinical champion for the promotion of tel- } \\
\text { ephonic/video counseling }\end{array}$ & 3.32 & $3.18-3.46$ & 3.63 & $3.49-3.77$ & 0.31 & 0.18 to 0.44 & $<0.001$ \\
\hline Telephonic/video counseling is affordable to patients & 4.02 & $3.89-4.14$ & 3.78 & $3.66-3.91$ & -0.23 & -0.36 to -0.11 & $<0.001$ \\
\hline Most of our patients can access telephonic/video technology & 3.97 & $3.84-4.10$ & 3.10 & $2.97-3.23$ & -0.87 & -1.02 to -0.73 & $<0.001$ \\
\hline Patients find telephonic/video counseling is easy to use & 3.93 & $3.80-4.05$ & 3.47 & $3.34-3.59$ & -0.46 & -0.59 to -0.33 & $<.001$ \\
\hline Patients want telephonic/video counseling to be sustained & 3.83 & $3.70-3.96$ & 3.75 & $3.62-3.87$ & -0.08 & -0.20 to 0.03 & 0.16 \\
\hline $\begin{array}{l}\text { Staff has been properly trained in telephonic/video coun- } \\
\text { seling }\end{array}$ & 3.66 & $3.54-3.79$ & 3.68 & $3.55-3.80$ & 0.01 & -0.10 to 0.13 & 0.82 \\
\hline $\begin{array}{l}\text { Staff, facilities, and equipment, job descriptions, policies, } \\
\text { are in place for sustaining telephonic/video counseling }\end{array}$ & 3.60 & $3.46-3.73$ & 3.65 & $3.51-3.78$ & 0.05 & -0.08 to 0.18 & 0.43 \\
\hline Staff want telephonic/video counseling to be sustained & 3.84 & $3.71-3.97$ & 4.03 & $3.91-4.16$ & 0.19 & 0.07 to 0.31 & 0.001 \\
\hline $\begin{array}{l}\text { Telephonic/video counseling easily integrates into our } \\
\text { workflow }\end{array}$ & 3.80 & $3.68-3.92$ & 3.85 & $3.72-3.97$ & 0.05 & -0.07 to 0.16 & 0.43 \\
\hline $\begin{array}{l}\text { We are adequately reimbursed for the services we provide } \\
\text { with telephonic/video counseling during COVID-19 }\end{array}$ & 3.46 & $3.32-3.59$ & 3.66 & $3.53-3.80$ & 0.20 & 0.08 to 0.33 & 0.001 \\
\hline $\begin{array}{l}\text { We anticipate being adequately reimbursed for the services } \\
\text { we provide with telephonic/video counseling after } \\
\text { COVID-19 }\end{array}$ & 3.18 & $3.04-3.32$ & 3.45 & $3.31-3.59$ & 0.27 & 0.14 to 0.40 & $<0.001$ \\
\hline $\begin{array}{l}\text { We have the billing expertise to support use of telephonic/ } \\
\text { video counseling in our organization }\end{array}$ & 3.71 & $3.58-3.84$ & 3.82 & $3.69-3.95$ & 0.11 & -0.01 to 0.22 & 0.071 \\
\hline $\begin{array}{l}\text { We have the information technology expertise to support the } \\
\text { use of telephonic/video counseling in our organization }\end{array}$ & 3.76 & $3.63-3.89$ & 3.80 & $3.67-3.93$ & 0.04 & -0.08 to 0.16 & 0.55 \\
\hline
\end{tabular}

with telephonic/video counseling after COVID-19 (0.27, 95\% Cl 0.14-0.20, p<0.001).

The TAM posits that if a technology is Easy to Use and has Perceived Usefulness, it will lead to Intent to Use, resulting in actual use (Al-Emran et al., 2018; Szajna, 1996; Venkatesh \& Bala, 2008). When this model is working as hypothesized and validated, Perceived Usefulness will mediate the relationship between Perceived Ease of Use and Intent to Use. Within the mediational analysis for telephone, Perceived Ease of Use was significantly associated with Future Intent ( $p=0.011$ ) (Fig. 2). When Perceived Usefulness was added to the equation, there was a significant relationship between Perceived Ease of Use and Perceived Usefulness $(\mathrm{p}<0.001)$, between Perceived Usefulness and Future Intent $(\mathrm{p}<0.001)$, and the relationship between Perceived Ease of Use and Future Intent was no longer significant $(p=0.40)$. This signifies complete mediation. A similar set of relationships were found in the mediational analysis for intent to use video services with the path between Perceived Ease of Use and Future Intent significant at $p=0.003$ 
Fig. 2 Technology acceptance model for telephone/video SUD services
Mediation Analysis: future intent to use telephone services

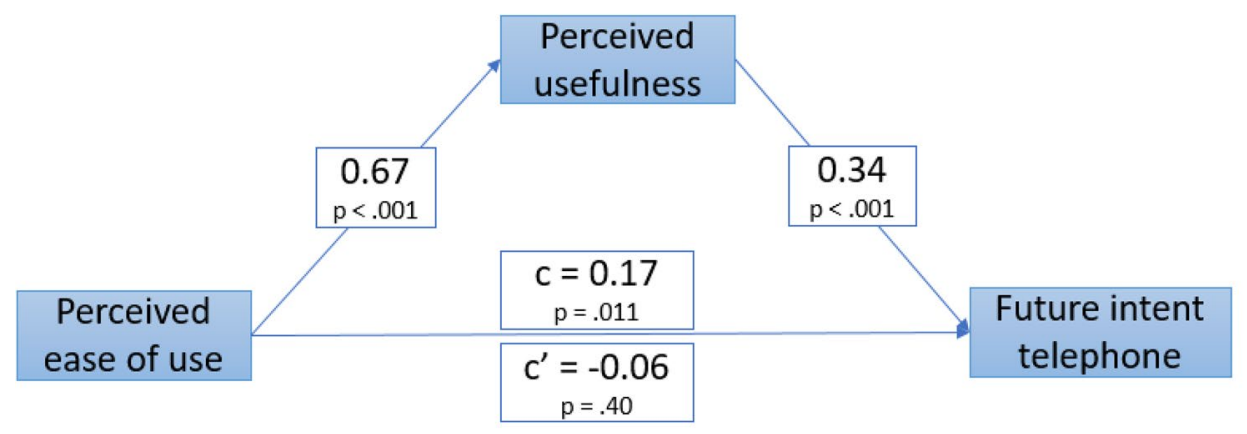

Mediation Analysis: future intent to use video services

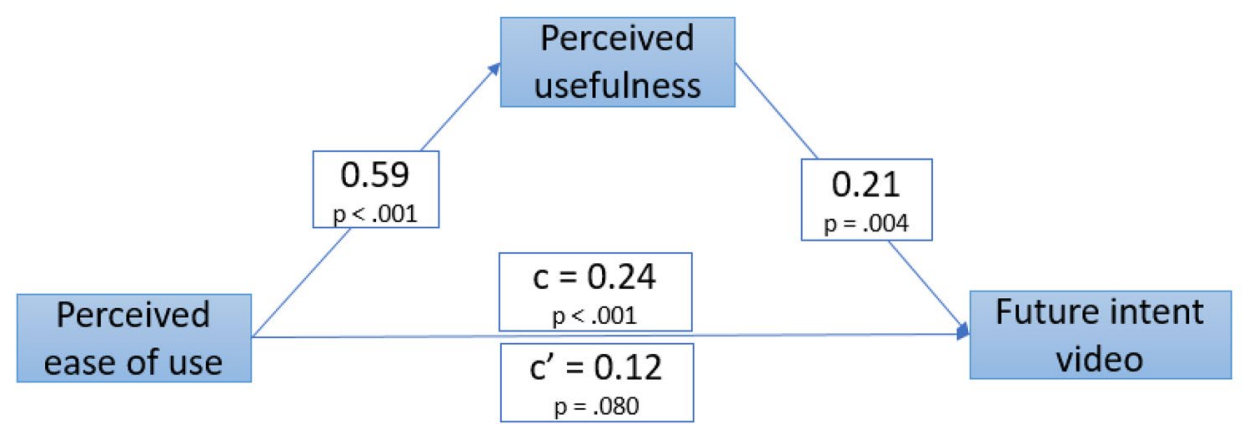

and not significant $(\mathrm{p}=0.067)$ when Perceived Usefulness was added to the model (Fig. 2).

\section{Discussion}

While telemental health has been in use for several decades, there has not been widespread, nationwide reliance on telehealth services within the mental health system until the recent changes prompted by the COVID-19 pandemic. In a very brief time span, most mental health services that could be provided remotely began to be delivered via telemental health. This study's results, representing various regions across the country, demonstrate that the majority of respondents were providing a wide array of mental health services via telephone or video conferencing. Those services that involve one clinician and one client, including individual therapy and screening and assessment, were being delivered by the greatest number of respondents. Services delivered by multi-disciplinary teams (e.g., Assertive Community Treatment) or involving multiple clients (e.g., group therapy) were more challenging to deliver remotely and were less likely to be offered via telehealth.

While the transition to telemental health has been challenging for some (Murphy et al., 2020), this survey supports that organizations and clinicians are likely to continue using telehealth after the pandemic has passed. There was a preference for the use of video-based telehealth over phone-based telehealth for the delivery of services. That being said, there was also support for the continued use of telephone services for all modalities except group therapy, medication management, and multi-disciplinary team-based services. Telephone services are recognized as more affordable, easier to use, and accessible for clients. The perceived usefulness of telephone and video services mediated the relationship between the perceived ease of use and the intent to use telehealth in the future.

The survey findings support the continued use of telehealth services offered by mental health providers and organizations, as respondents indicated a desire to use these services more following the pandemic. Results suggest that clinic leadership and staff support the implementation and sustainment of telephone and video counseling. A review or update of telehealth reimbursement guidelines and associated regulations may be warranted to support providers and organizations in these efforts. The survey results also highlight factors that mental health providers and organizations believe allow for increased patient accessibility; specifically, telephone services are affordable and easily accessible. As mental health providers and organizations seek to incorporate patient-centered approaches, telehealth services may allow for greater 
patient choice in seeking and receiving services. Although findings from this survey indicate video-based telehealth services are viewed more favorably than telephone-based services, additional research is needed to identify which service modality can be delivered the most effectively. Similarly, because of its perceived patient ease of use and accessibility, telephone delivery may be supported for some clients. Hence, a diverse mix of service delivery modalities, including in-person services, may be needed to maximize flexibility, outcomes, and patient preferences.

The survey findings should be understood in the context of at least three limitations that affect generalizability. First, the mental health providers and organizations responding to the survey were from a convenience sample pulled from four regional MHTTC databases representing 22 states. Second, the return rate for this survey was $18 \%$. Third, the survey's email distribution was the only recruitment modality used and could have limited reach and response had multiple distribution approaches been used.

Previous research on telemental health has established that it can be effective, improve client satisfaction, and reduce the overall cost of care (Hilty et al., 2013; Langarizadeh et al., 2017). However, there has been some reluctance to implement telehealth more fully throughout the mental health system. This hesitation has been attributed, in part, to challenges regarding the technological skills of clinicians and clients, training needs for clinicians, financial investment in equipment, insurance coverage for services, and regulatory and compliance concerns (Langarizadeh et al., 2017; Mace et al., 2018). The pressure created by the pandemic, the temporary loosening of regulatory restrictions, and the expansion of insurance reimbursement has facilitated the expansion of these services. In 2018, 47\% of survey respondents reported using telemental health (Mace et al., 2018). Just two years later, more than $89 \%$ were using telemental health for individual therapy in this study, resulting in a $42 \%$ increase in use. It is still unclear if the current telemental health services are being delivered with efficacy as those previously studied. This will have to be evaluated in the future.

In summary, the results demonstrate a large shift in telehealth use and provide an encouraging outlook for the use of telephone and video-based services after the COVID-19 pandemic. Future studies should continue to review the acceptance of these different service delivery approaches and their impact on care outcomes. In particular, integrating in-person, telephone, and video-based services to make them more patient-centered and achieve optimal outcomes should be studied in practice and research.

Funding This study was funded by the following Substance Use and Mental Health Administration (SAMHSA) Mental Health Technology
Transfer Center (MHTTC) Cooperative Agreements: H79SM081733, H79SM081783, H79SM081774, H79SM081792.

\section{Declarations}

Conflict of interest Author Molfenter has $<1 \%$ stock ownership in CHESS Mobile Health. CHESS Mobile Health does not provide or facilitate telephonic or video care delivery. Dr. Molfenter has worked extensively with his institution to manage any conflicts of interest.

Ethical Approval The University of Wisconsin Health Sciences Institutional Review Board granted an exemption for this research and approved the e-mail correspondence used to recruit survey participants (ID\#: 2020-0551).

Open Access This article is licensed under a Creative Commons Attribution 4.0 International License, which permits use, sharing, adaptation, distribution and reproduction in any medium or format, as long as you give appropriate credit to the original author(s) and the source, provide a link to the Creative Commons licence, and indicate if changes were made. The images or other third party material in this article are included in the article's Creative Commons licence, unless indicated otherwise in a credit line to the material. If material is not included in the article's Creative Commons licence and your intended use is not permitted by statutory regulation or exceeds the permitted use, you will need to obtain permission directly from the copyright holder. To view a copy of this licence, visit http://creativecommons.org/licenses/by/4.0/.

\section{References}

Al-Emran, M., Mezhuyev, V., \& Kamaludin, A. (2018). Technology Acceptance Model in M-learning context: A systematic review. Computers \& Education, 125, 389-412. https://doi.org/10.1016/j. compedu.2018.06.008

American Psychiatric Association. (2020). Telepsychiatry toolkit. Retrieved from https://www.psychiatry.org/psychiatrists/practice/ telepsychiatry/toolkit. Accessed November 3, 2020.

American Psychological Association. (2020, June). Psychologists embrace telehealth to prevent the spread of COVID-19. Retrieved from https://www.apaservices.org/practice/legal/technology/psych ologists-embrace-telehealth. Accessed November 3, 2020.

American Telemedicine Association (ATA). (2020). Learning \& development: Practice guidelines. Retrieved from https://www. americantelemed.org/resource/learning-development/. Accessed November 3, 2020.

Barnett, M. L., \& Huskamp, H. A. (2020). Telemedicine for mental health in the United States: Making progress, still a long way to go. Psychiatric Services (Washington, DC), 71(2), 197-198. https://doi.org/10.1176/appi.ps.201900555

Bashshur, R. L., Shannon, G. W., Bashshur, N., \& Yellowlees, P. M. (2016). The empirical evidence for telemedicine interventions in mental disorders. Telemedicine Journal and e-Health: The Official Journal of the American Telemedicine Association, 22(2), 87-113. https://doi.org/10.1089/tmj.2015.0206

Benavides-Vaello, S., Strode, A., \& Sheeran, B. C. (2013). Using technology in the delivery of mental health and substance abuse treatment in rural communities: A review. The Journal of Behavioral Health Services \& Research, 40(1), 111-120. https://doi.org/10. 1007/s11414-012-9299-6

Czeisler, M., Lane, R. I., Petrosky, E., Wiley, J. F., Christensen, A., Njai, R., ... Rajaratnam, S. M. W. (2020). Mental health, 
substance use, and suicidal ideation during the COVID-19 pandemic-United States, June 24-30, 2020. MMWR. Morbidity and Mortality Weekly Report, 69(32), 1049-1057. http://doi. org/https://doi.org/10.15585/mmwr.mm6932a1

Daniel, D. M., Norman, J., Davis, C., Lee, H., Hindmarsh, M. F., McCulloch, D. K., ... Sugarman, J. R. (2004). A state-level application of the chronic illness breakthrough series: Results from two collaboratives on diabetes in Washington State. Joint Commission Journal on Quality and Patient Safety, 30(2), 69-79. http://doi. org/https://doi.org/10.1016/s1549-3741(04)30008-0

Edirippulige, S., \& Armfield, N. R. (2017). Education and training to support the use of clinical telehealth: A review of the literature. Journal of Telemedicine and Telecare, 23(2), 273-282. https://doi. org/10.1177/1357633x16632968

Gustafson, D. H., Brennan, P. F., \& Hawkins, R. P. (2007). Investing in e-Health. Springer.

Hilty, D. M., Ferrer, D. C., Parish, M. B., Johnston, B., Callahan, E. J., \& Yellowlees, P. M. (2013). The effectiveness of telemental health: A 2013 review. Telemedicine and e-Health, 19(6), 444454. https://doi.org/10.1089/tmj.2013.0075

Langarizadeh, M., Tabatabaei, M. S., Tavakol, K., Naghipour, M., Rostami, A., \& Moghbeli, F. (2017). Telemental health care, an effective alternative to conventional mental care: A systematic review. Acta Informatica Medica, 25(4), 240-246. https://doi.org/ 10.5455/aim.2017.25.240-246

Mace, S., Boccanelli, A., \& Dormond, M. (2018). The use of telehealth within behavioral health settings: Utilization, opportunities, and challenges. Ann Arbor, MI: University of Michigan School of Public Health, Behavioral Health Workforce Research Center. Retrieved from https://behavioralhealthworkforce.org/wp-conte nt/uploads/2018/05/Telehealth-Full-Paper_5.17.18-clean.pdf

Moore, M. A., \& Munroe, D. D. (2020). COVID-19 brings about rapid changes in the telehealth landscape. Telemedicine and e-Health. https://doi.org/10.1089/tmj.2020.0228

Murphy, A. A., Karyczak, S., Dolce, J. N., Zechner, M., Bates, F., Gill, K. J., \& Rothpletz-Puglia, P. (2020). Challenges experienced by behavioral health organizations in New York resulting from COVID-19: A qualitative analysis. Community Mental Health Journal. https://doi.org/10.1007/s10597-020-00731-3

Petersen, D., Salazar, B., \& Kertz, S. J. (2020). Therapist and treatment-seeking students' perceptions of telemental health. Journal of Technology in Behavioral Science, 5(2), 113-120. https://doi. org/10.1007/s41347-019-00116-8

Pruitt, L. D., Luxton, D. D., \& Shore, P. (2014). Additional clinical benefits of home-based telemental health treatments. Professional
Psychology: Research and Practice, 45(5), 340-346. https://doi. org/10.1037/a0035461

Ramirez, H., Springmeyer, A., Weis, K., Espiritu, R., Wolf-Prusan, L., DeCelle, K., ... Clarke, B. L. (2020). Telehealth clinical and technical considerations for mental health providers. Pacific Southwest Mental Health Technology Transfer Center (MHTTC). Retrieved from https://cars-rp.org/_MHTTC/docs/Telehealth\% 20Clinical\%20Considerations.pdf

Shore, J. H., Schneck, C. D., \& Mishkind, M. C. (2020). Telepsychiatry and the coronavirus disease 2019 pandemic-Current and future outcomes of the rapid virtualization of psychiatric care. JAMA Psychiatry. https://doi.org/10.1001/jamapsychiatry.2020.1643

Szajna, B. (1996). Empirical evaluation of the revised technology acceptance model. Management Science, 42(1), 85-92.

Uscher-Pines, L., Cantor, J., Huskamp, H. A., Mehrotra, A., Busch, A., \& Barnett, M. (2020). Adoption of telemedicine services by substance abuse treatment facilities in the U.S. Journal of Substance Abuse Treatment, 117, 108060. https://doi.org/10.1016/j. jsat.2020.108060

Venkatesh, V., \& Bala, H. (2008). Technology acceptance model 3 and a research agenda on interventions. Decision Sciences, 39(2), 273-315. https://doi.org/10.1111/j.1540-5915.2008.00192.x

Venkatesh, V., Morris, M. G., Davis, G. B., \& Davis, F. D. (2003). User acceptance of information technology: Toward a unified view. MIS Quarterly. https://doi.org/10.2307/30036540

Waldeck, A., Srivastava, P., \& Picken, H. A. (2020, September). Emerging stronger from the COVID-19 crisis: Recover, reposition, and redesign. Retrieved from https://www.innosight.com/ insight/emerge-stronger-from-the-COVID-19-crisis-recover-repos ition-and-redesign/. Accessed November 3, 2020.

Wang, S., Wen, X., Dong, Y., Liu, B., \& Cui, M. (2020). Psychological influence of coronovirus disease 2019 (COVID-19) pandemic on the general public, medical workers, and patients with mental disorders and its countermeasures. Psychosomatics, 61(6), 616-624. https://doi.org/10.1016/j.psym.2020.05.005

World Health Organization. (2020). Timeline: WHO's COVID-19 response. Retrieved from https://www.who.int/emergencies/ diseases/novel-coronavirus-2019/interactive-timeline. Accessed November 4, 2020.

Publisher's Note Springer Nature remains neutral with regard to jurisdictional claims in published maps and institutional affiliations. 